\title{
Effects of matrine in combination with cisplatin on liver cancer
}

\author{
GAOYU HU ${ }^{1 *}, \mathrm{CONG} \mathrm{CAO}^{2 *}$, ZHIHUA DENG ${ }^{1}, \mathrm{JUN} \mathrm{LI}^{2}, \mathrm{XIHAN} \mathrm{ZHOU}^{1}, \mathrm{ZANSONG} \mathrm{HUANG}^{1}$ and CHAO CEN \\ Departments of ${ }^{1}$ Gastroenterology and ${ }^{2}$ General Medicine, Affiliated Hospital of Youjiang \\ Medical University for Nationalities, Baise, Guangxi 533000, P.R. China
}

Received June 24, 2020; Accepted November 2, 2020

DOI: $10.3892 / \mathrm{ol} .2020 .12327$

\begin{abstract}
Matrine, an alkaloid isolated from Sophora flavescens, promotes tumor cell apoptosis and strengthens the anticancer capacity of chemotherapeutic drugs. The present study aimed to investigate the inhibitory effect and underlying mechanism of matrine in combination with cisplatin on liver cancer progression. Tumor progression was studied in nude mice. The human liver cancer cell line HepG2 was injected into BALB/c nude mice subcutaneously to establish a tumor model. Mice were subsequently treated with matrine, cisplatin, matrine + cisplatin or normal saline. Nude mice and tumor growth were monitored. Tumors were excised and the expression of survivin, caspase-3, caspase-7 and caspase- 9 was detected by immunohistochemistry. Western blotting was used to determine the expression of survivin, caspase-3, caspase-7, caspase-9 and X-linked inhibitor of apoptosis protein (XIAP) in tumor tissues. The results demonstrated that matrine exerted anticancer effects in liver cancer-transplanted tumors, as evidenced by decrease in tumor weight and volume. Furthermore, the tumor inhibition rate in mice treated with matrine + cisplatin was $83.3 \%$, whereas it was of 37.5 and $75 \%$ in mice treated with matrine or cisplatin alone, respectively. In addition, the expression of survivin and XIAP was significantly downregulated, whereas the expression of caspase-3, caspase-7 and caspase- 9 was significantly upregulated in tumor tissues from nude mice treated with matrine + cisplatin, compared with those treated with cisplatin, matrine or normal saline. These findings suggested that the combination of matrine and cisplatin may promote tumor cell apoptosis in liver cancer by activating the caspase apoptosis pathway and suppressing the survivin-associated inhibition of caspase-9.
\end{abstract}

Correspondence to: Dr Zansong Huang or Dr Chao Cen, Department of Gastroenterology, Affiliated Hospital of Youjiang Medical University for Nationalities, 18 Zhongshan Second Road, Baise, Guangxi 533000, P.R. China

E-mail: 1019846481@qq.com

E-mail: cenchao2011@126.com

${ }^{*}$ Contributed equally

Key words: matrine, cisplatin, liver cancer, surviving, caspase

\section{Introduction}

Liver cancer is one of the most common malignant tumors worldwide and is a leading cause of cancer-associate mortality (1). The therapeutic strategies for liver cancer include surgery, liver transplantation, local ablation, interventional chemotherapy and biological drug targeted therapy (2). However, chemotherapy drug resistance and chemotoxicity can reduce the antitumor efficacy and patient tolerance (3-5). It is therefore crucial to develop novel non-toxic and efficient agents that could be used in combination with existing therapies for the treatment of patients with liver cancer.

Survivin, an inhibitor of the apoptosis protein family, is specifically expressed in tumors whereas it is under-expressed in normal adult differentiated mature tissues $(6,7)$. Survivin serves crucial roles in cell cycle and cell death by inhibiting apoptosis (8). Survivin inhibits apoptosis mainly via the intrinsic apoptotic pathway. In the intrinsic pathway, survivin overexpression can stabilize the activation of X-linked inhibitor of apoptosis protein (XIAP) and inhibit the caspase-3/9 apoptotic pathway (9). Furthermore, survivin is closely associated with liver cancer recurrence and therapeutic resistance. The results from a previous study including 60 patients demonstrated that the overall survival of patients is significantly higher in patients with negative expression of survivin at tumor margins. Furthermore, negative survivin expression in tumor tissues is associated with fewer extensive operations and the absence of vascular invasion (10). Therefore, due to its inhibiting effect on liver cancer cell apoptosis, survivin may be considered as a potential target for tumor gene therapy.

Matrine is a component isolated from Sophora flavescens (11). It has been reported to have anti-inflammatory, antiviral and antitumor effects, and has been used for treatment of chronic active hepatitis and hepatocellular carcinoma (HCC) (12). Previous studies have demonstrated that matrine can inhibit the proliferation and induce the apoptosis of SMMC-7721, HepG2 and BEL-7402 tumor cell lines in a dose-dependent manner (13-15). A recent study reported that the combination of matrine and cisplatin has some inhibitory effects on HCC cell proliferation and tumor growth and exhibits a reduced toxicity (16). However, further investigation is required to determine the underlying mechanisms of matrine + cisplatin in liver cancer.

The present study aimed to explore the antitumor effects of matrine combined with cisplatin in a nude mouse model transplanted with HepG2 liver cancer cells. 


\section{Materials and methods}

Main reagents. Matrine was obtained from Guangzhou Baiyun Shan Ming Xing Pharmaceutical, Co., Ltd. (cat. no. H10950071). Cisplatin was purchased from Qilu Pharmaceutical Co., Ltd. (cat. no. H37021358). Rabbit survivin (cat. no. A00379), caspase-3 (cat. no. BM3954), caspase-7 (cat. no. PA1442), caspase-9 (cat. no. BM4619), XIAP (cat. no. BA2620), $\beta$-actin (cat. no. BM3873) monoclonal primary antibodies and goat anti-mouse secondary IgG were obtained from Wuhan Boster Biological Technology, Ltd.

Nude mice. A total of 24 six-weeks-old BALB/c nude mice were purchased from the the Animal Experimental Center of Guangxi Medical University (Nanning, China; registration no. SCXK 2010-0002). Mice weighted 16-20 g and were housed under specific-pathogen-free conditions at a temperature of $22-26^{\circ} \mathrm{C}$ and a relative humidity of $40-60 \%$. All efforts were made to minimize animal suffering. Animal protocol was approved by the Ethical Committee of the Youjiang Medical University for Nationalities.

Cell culture. The $\mathrm{HepG}_{2}$ cell line was obtained from The Cell Bank of Type Culture Collection of the Chinese Academy of Sciences and was authenticated by the manufacturer using the STR method. HepG2 cells were cultured in RPMI-1640 medium (HyClone; Cytiva) supplemented with 10\% FBS (Zhejiang Tianhang Biotechnology Co., Ltd.) and placed at $37^{\circ} \mathrm{C}$ in a humidified incubator containing $5 \% \mathrm{CO}_{2}$. The medium was changed once every three days.

Tumor model and treatment. To generate the tumor model, nude mice were subcutaneously injected with a $200 \mu$ cell suspension containing $5 \times 10^{6} \mathrm{HepG} 2$ cells into the axillary region. The tumors grew to almost $6 \mathrm{~mm}$ after 10 days of inoculation, and a successful HepG2 tumor model was confirmed by cell morphology observation with hematoxylin-eosin (H\&E) staining. Subsequently, mice were randomly divided into four groups of six mice as follows: i) normal saline (NS) group, mice administered with NS; ii) matrine group, mice intraperitoneally injected with $100 \mathrm{mg} / \mathrm{kg}$ matrine; iii) cisplatin group, mice intraperitoneally injected with $2 \mathrm{mg} / \mathrm{kg}$ cisplatin; and iv) matrine + cisplatin group, mice intraperitoneally injected with $100 \mathrm{mg} / \mathrm{kg}$ matrine and $2 \mathrm{mg} / \mathrm{kg}$ cisplatin. Drugs were intraperitoneally injected five days per week for three weeks. The reactivity and behavior of mice in the cages were observed. The length and width of the tumors were measured on days $7,10,12,14,17,19$ and 21 using a Vernier caliper, and the weight of the mice was recorded. The tumor volume was calculated using the formula: Tumor volume $=0.5 \mathrm{x}$ length $\mathrm{x}(\text { width })^{2}$. Mice were sacrificed by cervical dislocation at the end of the treatment period. The sacrifice of mice was confirmed by the sound of cervical spine fracture and the absence of breathing.The tumors were excised, one part was stored at $-80^{\circ} \mathrm{C}$ for western blotting and another part was fixed for further staining. The tumor inhibition rate was analyzed using the following formula: Tumor inhibition rate $(\%)=(1$-average weight of tumors in treatment group/average weight of tumors in control group) $\mathrm{x} 100$.

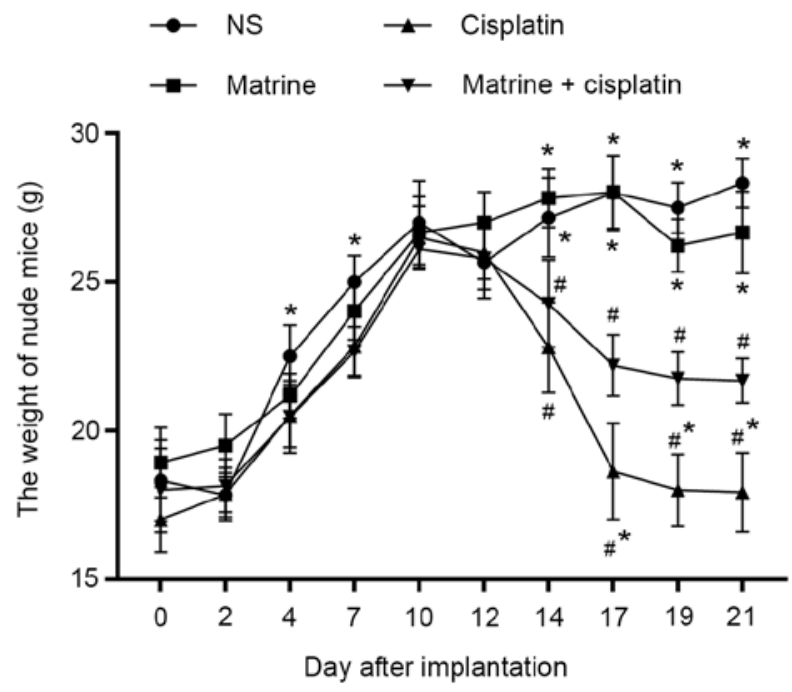

Figure 1. Effects of matrine in combination with cisplatin on the weight of $\mathrm{HepG}_{2}$ transplanted nude mice. Evolution of $\mathrm{HepG}_{2}$ transplanted nude mice body weight during 21 days of treatment with matrine and/or cisplatin ( $\mathrm{n}=6$ per group). ${ }^{\text {}} \mathrm{P}<0.05$ vs. matrine group and ${ }^{*} \mathrm{P}<0.05$ vs. cisplatin group. NS, normal saline.

Histological analysis. Tumor tissues were harvested and fixed in $4 \%$ formaldehyde for $24 \mathrm{~h}$ at room temperature. The samples were then dehydrated using increasing ethanol gradient $(75,85,95 \%$ and anhydrous ethanol), embedded in paraffin and cut into $4-\mu \mathrm{m}$ sections. Subsequently, dried slices were dewaxed using xylene twice for $5 \mathrm{~min}$ followed by $100,95,85$ and $75 \%$ ethanol for $2 \mathrm{~min}$. Sections were stained by hematoxylin for $8-15 \mathrm{~min}$ and differentiated by $1 \%$ hydrochloric alcohol for $10 \mathrm{sec}$. Finally, sections were blocked for $\mathrm{H} \& \mathrm{E}$ staining after bluing under $50^{\circ} \mathrm{C}$ water. Histopathological examination was performed under a light microscope (Leica Microsystems, Inc.).

Immunohistochemical (IHC) staining. IHC staining was performed according to the manufacturers' instructions. Briefly, the tumor tissue slices were incubated with $0.3 \%$ hydrogen peroxide for $10 \mathrm{~min}$ at room temperature and washed with PBS. Sections were incubated with goat anti-mouse secondary $\operatorname{IgG}(1: 500)$ at $4^{\circ} \mathrm{C}$ overnight, washed three times with PBS and incubated with secondary antibody $(1: 4,000)$ at room temperature for $30 \mathrm{~min}$. The tumor sections were then visualized for 3-15 min using DBA solution. Eventually, slides were counterstained with hematoxylin for 8-15 min at room temperature. Cells positively stained were colored as brownish-yellow and were counted in 10 random fields per section using a light microscope (magnification, $\mathrm{x} 400$ ). The rate of positive cells was calculated using the following formula: Positive cell rate $(\%)=$ number of positive cells/tumor cells $\times 100 \%$.

Western blotting. Tumor samples were thawed and cut into small pieces. Tissues were lysed using a western blotting lysis kit (cat. no. P0013B; Beyotime Institute of Biotechnology) at $4^{\circ} \mathrm{C}$. Protein concentration was detected using the BCA method and proteins were separated by $10 \%$ SDS-PAGE and transferred onto PVDF membranes. Membranes were incubated with primary antibodies against survivin, caspase-3, 


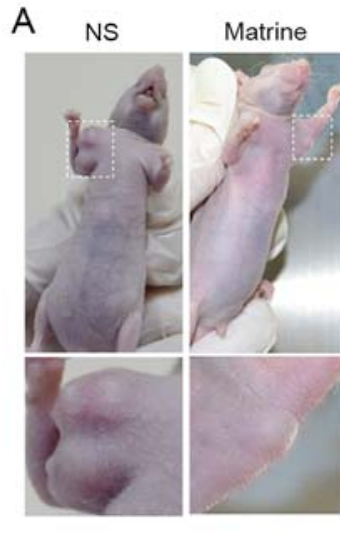

C

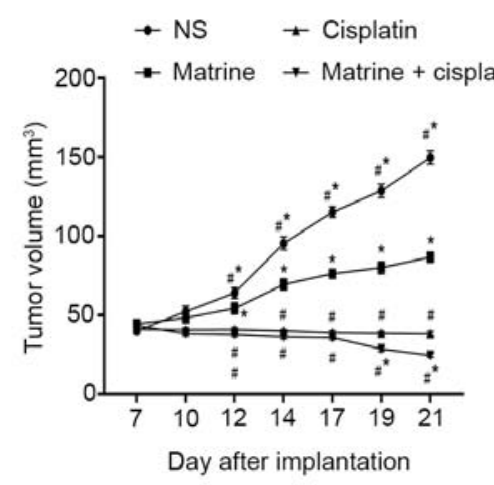

Cisplatin Matrine + Cisplatin
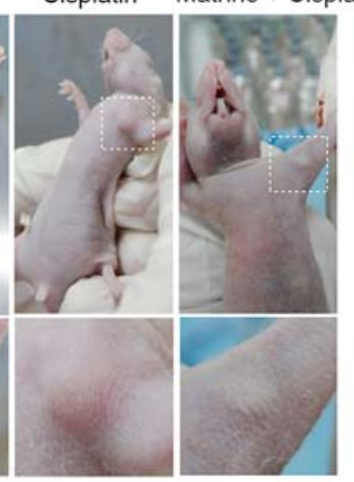

D

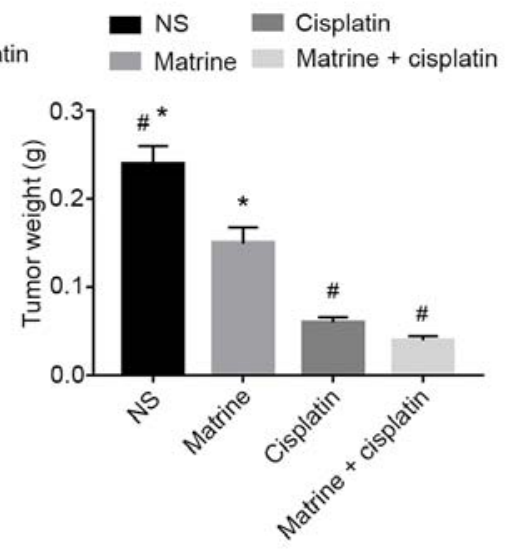

B

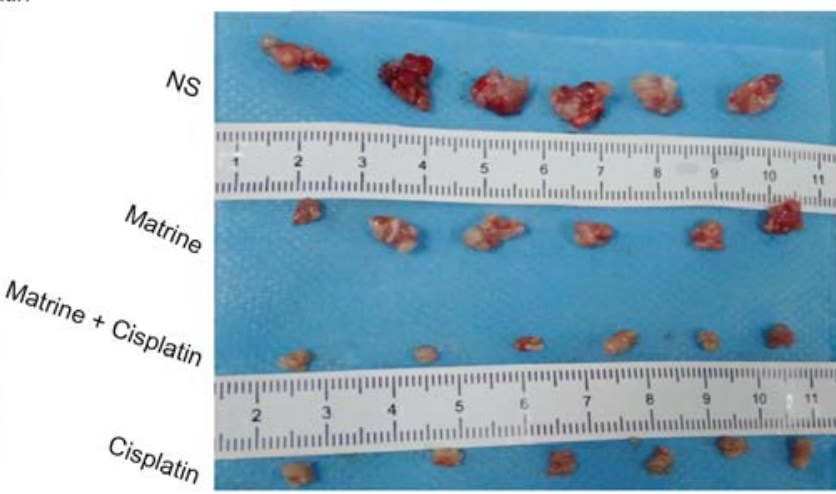

E

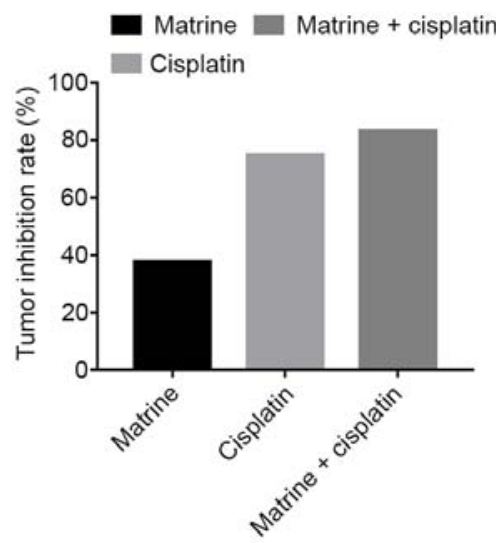

Figure 2. Matrine in combination with cisplatin inhibits tumor progression in $\mathrm{HepG}_{2}$ transplanted tumor mice. (A) Tumor development 21 days after injection of $\mathrm{HepG}_{2}$ cells. Magnified images display transplanted tumor tissues at injection site ( $\mathrm{n}=6$ per group). (B) Resected tumors from each group ( $\mathrm{n}=6$ per group). (C) Comparison of tumor volume between matrine + cisplatin group and the control group in $\mathrm{HepG}_{2}$ transplanted nude mice ( $\mathrm{n}=6$ per group). (D) Comparison of tumor weight between matrine + cisplatin group and the control group in $\mathrm{HepG}_{2}$ transplanted nude mice ( $\mathrm{n}=6$ per group). (E) Tumor inhibition rate was expressed as a percentage of the NS group. ${ }^{\#} \mathrm{P}<0.05$ vs. matrine group and ${ }^{*} \mathrm{P}<0.05$ vs. cisplatin group. NS, normal saline.

caspase-7, caspase-9, XIAP and $\beta$-actin diluted in blocking buffer $(1: 10,000)$ overnight at $4^{\circ} \mathrm{C}$, and with HRP-conjugated secondary antibody for $1 \mathrm{~h}$ at room temperature. Bands were developed on X-ray films using enhanced chemiluminescence substrate (Super Signal West Pico; Pierce; Thermo Fisher Scientific, Inc.). Densitometric analysis was performed using a UV light box (Gel Doc XR+; Bio-Rad Laboratories, Inc.).

Statistical analysis. Data were presented as the means \pm standard deviation. Statistical analysis was performed using SPSS 16.0 (SPSS Inc.) and GraphPad Prism v7.0 (GraphPad Software, Inc.). Statistical differences between groups were analyzed using one-way ANOVA followed by Tukey's post hoc test. $\mathrm{P}<0.05$ was considered to indicate a statistically significant difference.

\section{Results}

Growing of HepG2-transplanted nude mice. Nodules were detected at the inoculation site $\sim 7$ days after HepG2 cell injection, and tumors grew to almost $6 \mathrm{~mm}$ in size after 10 days of inoculation, with a $100 \%$ success rate.

As presented in Fig. 1, the weight of nude mice treated with NS increased by 1-3 g every two days, and stabilized at 26-28 g. The weight of nude mice in the matrine group was $27 \mathrm{~g}$ at the end of the experiment. Mice in both NS and matrine groups presented with no abnormal mental state, indicating that matrine had no significant adverse effects on the development of HepG2-transplanted nude mice. Conversely, nude mice treated with cisplatin showed poor mental health and a less active behavior than those treated with NS. Furthermore, treatment with cisplatin significantly decreased the body weight to $\sim 17 \mathrm{~g}$. However, the body weight in matrine + cisplatin group was higher than that in the cisplatin group at the end of the experiment $(\sim 22 \mathrm{~g})$.

Matrine in combination with cisplatin inhibits tumor growth. Matrine + cisplatin was administered in HepG2-transplanted nude mouse model to observe its effect on tumor progression. The results demonstrated that treatment with matrine significantly decreased tumor volume compared with NS or cisplatin groups. In addition, the tumor growth rate was significantly decreased in mice treated with matrine + cisplatin compared with NS group (Fig. 2A-C). Furthermore, as presented in Fig. 2D, the tumor weight of mice treated with matrine $(0.15 \pm 0.018 \mathrm{~g})$, cisplatin $(0.06 \pm 0.006 \mathrm{~g})$ and matrine + cisplatin $(0.04 \pm 0.005 \mathrm{~g})$ was significantly decreased compared with NS group $(0.24 \pm 0.02 \mathrm{~g})$. Furthermore, treatment with matrine + cisplatin resulted in tumor inhibition rate of $83.3 \%$, whereas treatment with matrine- and cisplatin-alone 

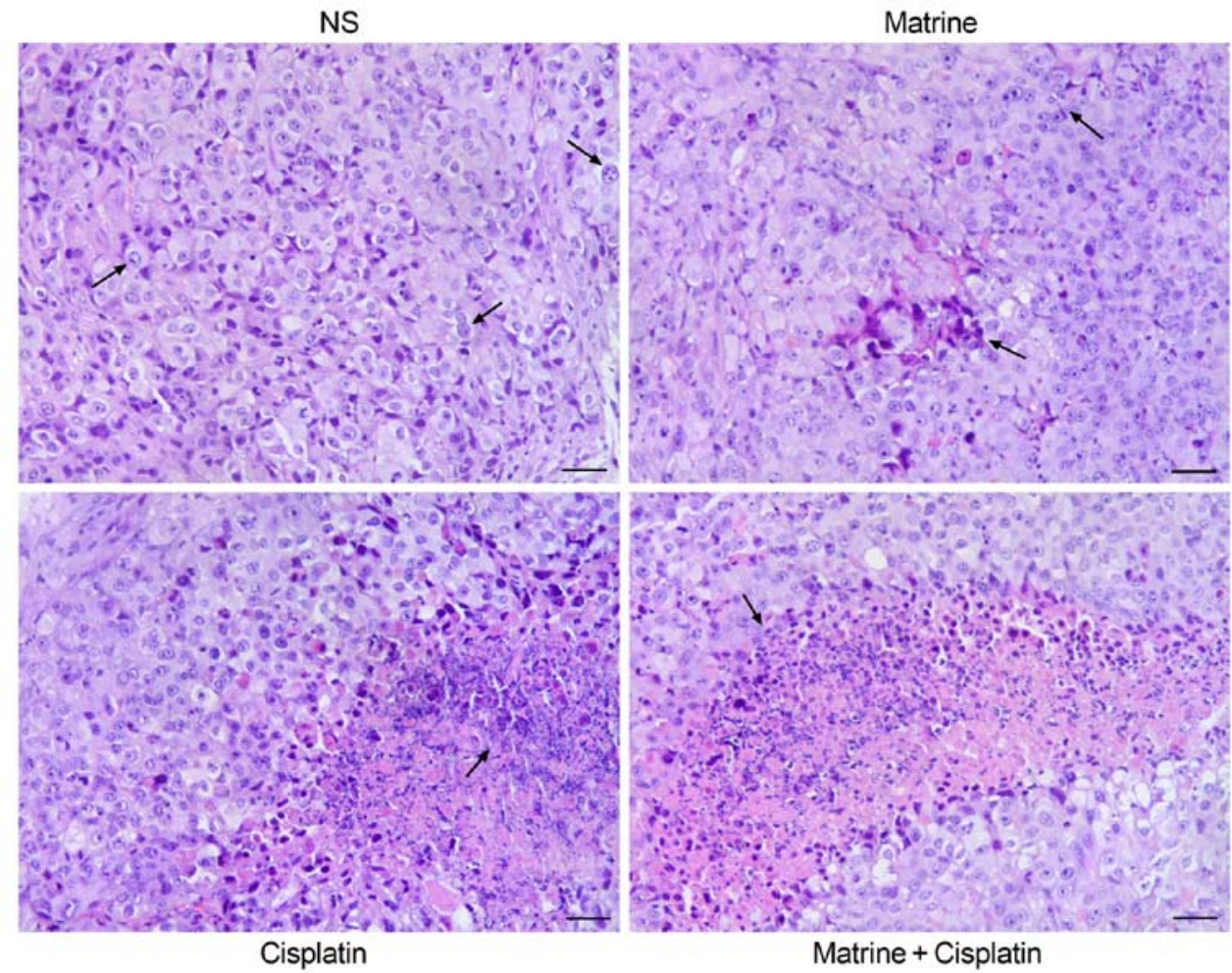

Figure 3. Morphology of nude mice transplanted tumors following hematoxylin-eosin staining. Magnification, x20. Scale bar, $50 \mu \mathrm{m}$. NS, normal saline.

resulted in inhibition rates of 37.5 and $75 \%$, respectively, in HepG2-transplanted nude mice (Fig. 2E).

Tumor tissue morphology. Morphology of the tumor tissue under the microscope was similar to that of the primary liver tumor. The tumor cells were of various sizes. Nuclei were stained intensely. The nucleocytoplasmic ratio was enlarged, and most of the nuclei were divided. Few tumor cells showed fatty degeneration and a transparent cytoplasm. In the NS group, a few apoptotic tumor cells were scattered in the tumor tissue. Furthermore, more apoptotic cells were seen in tumor tissue of mice treated with matrine, where sheet-like focal areas of coagulative necroses could be seen. In addition, increased apoptosis and coagulative necroses were observed in the cisplatin group, in particular in the combination group. These results suggested that matrine may promote tumor cell apoptosis when combined with cisplatin (Fig. 3).

Survivin is downregulated following mice treatment with matrine and cisplatin. Since survivin is associated with recurrence and therapeutic resistance in liver cancer, the present study analyzed whether matrine and cisplatin could affect survivin expression. The results demonstrated that individual treatment with matrine and cisplatin decreased the number of cells positive to survivin to $62.50 \pm 8.09$ and $38.67 \pm 8.26 \%$, respectively, compared with NS group $(83.26 \pm 15.56 \%$; Fig. 4A and B). Furthermore, the expression of survivin was significantly decreased in mice treated with matrine + cisplatin $(19.58 \pm 4.52 \%)$ compared with those treated with cisplatin only (Fig. 4C and D). The results from western blotting were similar to that of IHC. In addition, the expression of XIAP, a downstream protein to survivin, was significantly downregulated following combined treatment with matrine and cisplatin (Fig. 4C and D).

Matrine in combination with cisplatin activates the caspase apoptotic pathway. To investigate the molecular mechanism underlying the anticancer role of matrine in liver cancer, the protein expression profiles of caspase-3, caspase- 7 and caspase- 9 was investigated in tumor tissues from mice treated with matrine, cisplatin or both. The results demonstrated that the rate of cells positive to caspase-3, caspase- 7 and caspase -9 in the NS group were $21.15 \pm 3.68,20.61 \pm 5.87$ and $25.39 \pm 6.80 \%$, respectively. However, this rate was significantly increased in the matrine $(35.13 \pm 10.57,38.45 \pm 12.08$ and $28.79 \pm 10.05 \%$, respectively), cisplatin $(65.88 \pm 4.8,47.33 \pm 10.65$ and $42.09 \pm 9.19 \%$, respectively) and combination treatment $(78.26 \pm 6.09,68.13 \pm 13.01$ and $82.37 \pm 14.11 \%$, respectively) groups compared with the NS group (Fig. 4B). The results from western blotting were consistent with that of IHC, indicating that the caspase apoptotic pathway may be activated following mice treatment with matrine and cisplatin.

\section{Discussion}

Chemoresistance and chemotoxicity affect the antitumor efficacy and patient tolerance to chemotherapy. Drug combination therapy is therefore a common and efficient strategy for cancer treatment. Matrine, an active component of Sophora flavescens, has antitumor effects in breast, ovarian, non-small cell lung and colorectal cancers, similarly to that of cisplatin in liver cancer (17-19). A study by Li et al (20) reported that treatment with matrine in combination with docetaxel inhibits the proliferation and migration of tumor 
A

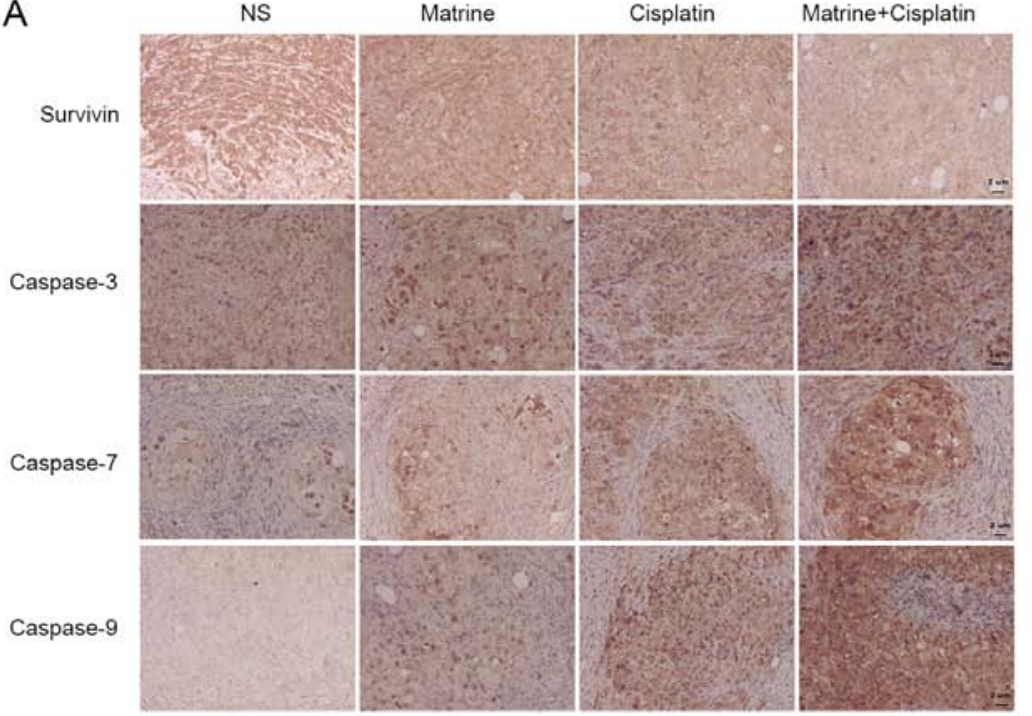

C
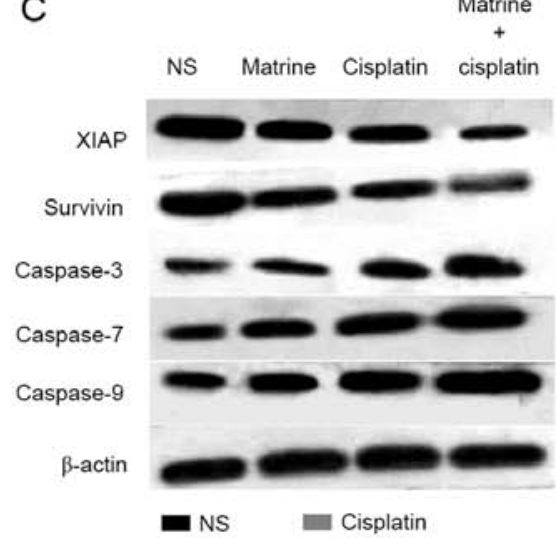

Matrine Matrine + Cisplatin

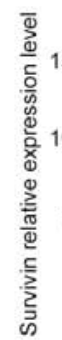

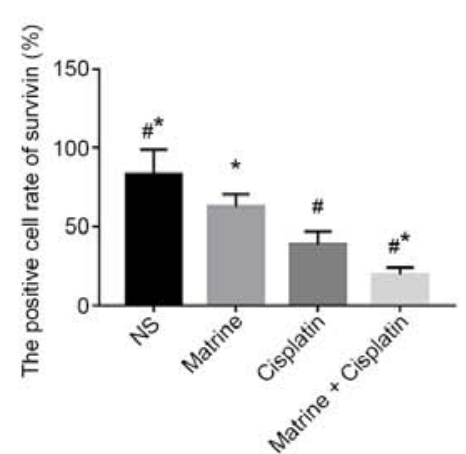
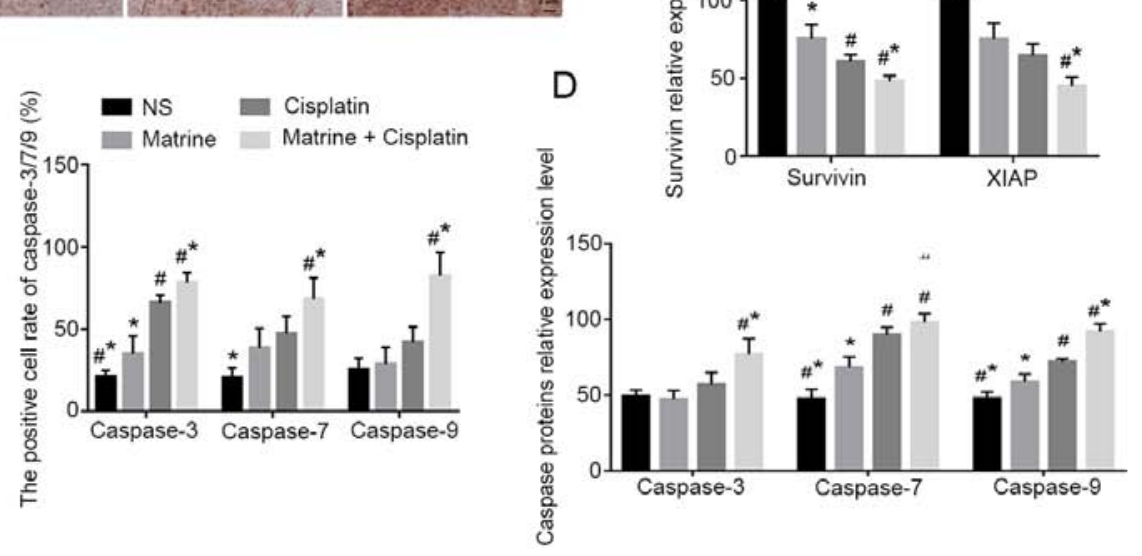

Figure 4. Matrine in combination with cisplatin regulated the expression of survivin, XIAP, caspase-3, caspase-7 and caspase-9 in HepG ${ }_{2}$ transplanted nude mice. (A and B) Expression of survivin, caspase-3, caspase-7 and caspase-9 in tumor tissues was assessed by immunohistochemistry (magnification, $\mathrm{x} 400$; scale bar, $20 \mu \mathrm{m}$ ) and quantitatively analyzed ( $\mathrm{n}=6$ per group). (C and D) Expression of survivin, XIAP, caspase-3, caspase-7 and caspase-9 in tumor samples was analyzed by western blotting and quantified ( $\mathrm{n}=6$ per group). ${ }^{*} \mathrm{P}<0.05$ vs. matrine group and ${ }^{*} \mathrm{P}<0.05$ vs. cisplatin group. NS, normal saline; XIAP, $\mathrm{X}-\mathrm{linked}$ inhibitor of apoptosis protein.

cells in androgen-resistant prostate cancer, indicating the potential antitumor effects of matrine in combination with chemotherapeutic drugs. A previous study from our laboratory demonstrated that matrine in combination with cisplatin exerts a favorable antitumor effect in liver cancer (16). However, the underlying mechanisms remain unknown.

The subcutaneously transplanted mouse tumor model is widely used to establish tumor models and study the efficacy of drugs (21). In the present study, the liver cancer mice model was successfully established following subcutaneous injection of HepG2 cells, with a tumor success rate of $100 \%$.

Survivin is a member of the IAPs family that has been reported to be strongly associated with cell proliferation, cell cycle control and apoptosis $(22,23)$. Previous studies have determined the medical roles of survivin in numerous malignancies, including liver cancer. A study by Ikeguchi et al (24) reported higher recurrence rates and lower one- and three-year survival rates in survivin-positive HCC patients compared with survivin-negative patients. Furthermore, the proliferation of hepatoma cells is significantly inhibited following survivin knockdown, promoting hepatoma cell apoptosis and inhibition of tumor growth in nude mice (25). Survivin serves therefore a crucial role in the progression of liver cancer. A previous study demonstrated that the proliferation index in survivin-positive liver cancer is higher than that in survivin-negative liver cancer, which may be related to the inhibitory effect of survivin in the caspase pathway (26). In the present study, matrine + cisplatin significantly inhibited the expression of survivin, resulting in the inhibition of tumor growth and lower mice tumor weights. The overexpression of survivin leads to formation of complex with XIAP that inhibit apoptosis via binding with members of the caspase family, in particular caspase-3, caspase-7 and caspase-9 (8), suggesting that inhibition of survivin could contribute to tumor apoptosis. In addition, overexpression of procaspase can lead to proenzyme activation, indicating that caspase proenzyme promotes auto-activation at high concentrations (27). These studies indicate that inhibiting surviving expression may be considered as an effective antitumor strategy. In the present study, IHC and western blotting were performed to analyze the regulatory effect of matrine + cisplatin on surviving expression. The results demonstrated that treatment with matrine in combination with cisplatin inhibited the overexpression of survivin, reduced the inhibitory effect of 
survivin on the downstream caspase pathway and promoted tumor cell apoptosis.

In the present study, matrine presented some antitumor effect similar to that of cisplatin. Furthermore, the effects of matrine + cisplatin were better than that of cisplatin alone. In addition, the changes in mice weight and behavioral and psychological observations indicated that matrine may reduce the side effects of cisplatin in liver cancer nude mice.

In summary, the present study demonstrated that matrine in combination with cisplatin exerted inhibitory effects on progression of liver cancer progression by promoting apoptosis via suppression of survivin and activation of the caspase pathway. Although our work has confirmed the efficacy of matrine in combination with cisplatin on liver cancer treatment, further investigation is required to confirm the results on apoptosis. To do so, future work will focus on the detection of apoptosis-related indicators, such as TUNEL staining, in vitro and in vivo, and the determination of the underlying mechanism of matrine + cisplatin on cell apoptosis. The results from the present study may significantly contribute to the literature, and further investigation in patients with liver cancer may validate the efficacy of matrine in preventing chemotherapy resistance.

\section{Acknowledgements}

Not applicable.

\section{Funding}

The present study was supported by the Natural Science Foundation of Guangxi Zhuang Autonomous Region (grant no. 2014GXNSFAA118143), the Science and Technology Base and Talents Special Project of Guangxi (Research Project of Guangxi Clinical Medical Research Center for Hepatobiliary Diseases; grant no. Guike AD17129025), the 2017 Medical and Health Self-financing Project of Guangxi (grant no. Z20170224) and the Innovation Project of Guangxi Graduate Education (grant no. YCSW2020235).

\section{Availability of data and materials}

The data sets generated and/or analyzed during the present study are available from the corresponding author on reasonable request.

\section{Authors' contributions}

$\mathrm{ZH}$ and CCe substantially contributed to the conception and design of the study. GH and CCa performed experiments, analyzed data and drafted the manuscript. ZD, JL and XZ performed experiments and interpreted data. All authors read and approved the final version.

\section{Ethics approval and consent to participate}

Animal experiments were approved by the Ethical Committee of Youjiang Medical University For Nationalities (Baise, China).

\section{Patient consent for publication}

Not applicable.

\section{Competing interests}

The authors declare that they have no competing interests.

\section{References}

1. Bray F, Ferlay J, Soerjomataram I, Siegel RL, Torre LA and Jemal A: Global cancer statistics 2018: GLOBOCAN estimates of incidence and mortality worldwide for 36 cancers in 185 countries. CA Cancer J Clin 68: 394-424, 2018.

2. Chan SL and Yeo W: Development of systemic therapy for hepatocellular carcinoma at 2013: Updates and insights. World J Gastroenterol 20: 3135-3145, 2014.

3. Wei YP, Shen NJ, Wang ZC, Yang GS, Yi B, Yang N, Qiu YH and Lu JH: Sorafenib sensitizes hepatocellular carcinoma cell to cisplatin via suppression of $\mathrm{Wnt} / \beta$-catenin signaling. Mol Cell Biochem 381: 139-144, 2013.

4. Jung SH, Kim HJ, Oh GS, Shen A, Lee S, Choe SK, Park R and So HS: Capsaicin ameliorates cisplatin-induced renal injury through induction of heme oxygenase-1. Mol Cells 37: 234-240, 2014.

5. Jin J, Ye MC, Wang LP, Li RX, Zhou Y, Wang Y, Zhu WZ, Zuo Y and Liu SH: Grade IV Myelosuppression after induction chemotherapy of TPF on oral cancer: Clinical analysis of 29 cases. Shanghai Kou Qiang Yi Xue 23: 219-223, 2014 (In Chinese).

6. Ambrosini G, Adida C and Altieri DC: A novel anti-apoptosis gene, survivin, expressed in cancer and lymphoma. Nat Med 3: 917-921, 1997.

7. Fenstermaker RA, Figel SA, Qiu JX, Barone TA, Dharma SS, Winograd EK, Galbo PM, Wiltsie LM and Ciesielski MJ: Survivin monoclonal antibodies detect survivin cell surface expression and inhibit tumor growth in vivo. Clin Cancer Res 24: 2642-2652, 2018.

8. Altieri DC: Survivin in apoptosis control and cell cycle regulation in cancer. Prog Cell Cycle Res 5: 447-452, 2003.

9. Dohi T, Okada K, Xia F, Wilford CE, Samuel T, Welsh K, Marusawa $\mathrm{H}$, Zou H, Armstrong R, Matsuzawa S, et al: An IAP-IAP complex inhibits apoptosis. J Biol Chem 279: 34087-34090, 2004.

10. Kapiris I, Nastos K, Karakatsanis A, Theodosopoulos T, Karandrea D, Pafiti AK and Contis J: Survivin expression in hepatocellular carcinoma. Correlation with clinicopathological characteristics and overall survival. J BUON 24: 1934-1942, 2019.

11. Chu YJ, Ma WD, Thome R, Ping JD, Liu FZ, Wang MR, Zhang ML, Zhang GX and Zhu L: Matrine inhibits CNS autoimmunity through an IFN- $\beta$-dependent mechanism. Front Immunol 11: 569530, 2020.

12. Wang L, Gao C, Yao SK and Xie B: Blocking autophagic flux enhances matrine-induced apoptosis in human hepatoma cells. Int J Mol Sci 14: 23212-23230, 2013.

13. Zheng YM, Li X, Zhao HY and Zhao JY: Effect of matrine and oxymatrine on proliferation and expression of Stat3 and Stat5 in SMMC-7721 cell line. Zhongguo Zhong Yao Za Zhi 33: 2234-2237, 2008 (In Chinese).

14. Qin XG, Hua Z, Shuang W, Wang YH and Cui YD: Effects of matrine on HepG2 cell proliferation and expression of tumor relevant proteins in vitro. Pharm Biol 48: 275-281, 2010.

15. Wu LC, Liu SB, Wei JR, Li D, Liu X, Wang JY and Wang LS: Synthesis and biological evaluation of matrine derivatives as anti-hepatocellular cancer agents. Bioorg Med Chem Lett 26: 4267-4271, 2016.

16. Hu J, Huang ZS, Hu GY and Huang MY: Oxymatrine combined with cisplatin enhances expression of vascular endothelial growth factor and CD31 in subcutaneous Xenografts of human hepatocellular carcinoma in nude mice. J Third Military Med Univ 40: 136-140, 2018.

17. Li X, Liang T, Chen SS, Wang M, Wang R, Li K, Wang JC, Xu CW, Du N, Qin S and Ren H: Matrine suppression of self-renewal was dependent on regulation of LIN28A/Let-7 pathway in breast cancer stem cells. J Cell Biochem 121: 2139-2149, 2020. 
18. Pu JT, Tang XJ, Zhuang X, Hu Z, He KM, Wu YF and Dai TY: Matrine induces apoptosis via targeting CCR7 and enhances the effect of anticancer drugs in non-small cell lung cancer in vitro. Innate Immun 24: 394-399, 2018.

19. Gu YY, Chen MH, May BH, Liao XZ, Liu JH, Tao LT, Man-Yuen Sze D, Zhang AL and Mo SL: Matrine induces apoptosis in multiple colorectal cancer cell lines in vitro and inhibits tumour growth with minimum side effects in vivo via Bcl-2 and caspase-3. Phytomedicine 51: 214-225, 2018.

20. Li Q, Xu J, He Z, Wen X, Wang F, Zhang P, Li J, Song B, Wang Q, Li R and Huang $\mathrm{H}$ : The effects of matrine in combination with docetaxel on castration-resistant (Androgen-Independent) prostate cancer. Cancer Manag Res 11: 10125-10133, 2019.

21. Brognaro E: 'The development tumor model' to study and monitor the entire progression of both primary and metastatic tumors. Tumour Biol 35: 2219-2230, 2014.

22. Suzuki A, Hayashida M, Ito T, Kawano H, Nakano T, Miura M, Akahane K and Shiraki K: Survivin initiates cell cycle entry by the competitive interaction with Cdk4/p16 ${ }^{\mathrm{INK} 4 \mathrm{a}}$ and $\mathrm{Cdk} 2 /$ cyclin E complex activation. Oncogene 19: 3225-3234, 2000.

23. Suzuki A, Ito T, Kawano H, Hayashida M, Hayasaki Y, Tsutomi Y, Akahane K, Nakano T, Miura M and Shiraki K: Survivin initiates procaspase 3/p21 complex formation as a result of interaction with Cdk4 to resist Fas-mediated cell death. Oncogene 19: 1346-1353, 2000.
24. Ikeguchi M, Ueda T, Sakatani T, Hirooka Y and Kaibara N: Expression of survivin messenger RNA correlates with poor prognosis in patients with hepatocellular carcinoma. Diagn Mol Pathol 11: 33-40, 2002.

25. Zhang R, Ma L, Zheng M, Ren J, Wang T, Meng Y, Zhao J, Jia L, Yao L, Han H, et al: Survivin knockdown by short hairpin RNA abrogates the growth of human hepatocellular carcinoma xenografts in nude mice. Cancer Gene Ther 17: 275-288, 2010.

26. Dai DJ, Lu CD, Lai RY, Guo JM, Meng H, Chen WS and Gu J: Survivin antisense compound inhibits proliferation and promotes apoptosis in liver cancer cells. World J Gastroenterol 11: 193-199, 2005.

27. Thornberry NA and Lazebnik Y: Caspases: Enemies within. Science 281: 1312-1316, 1998

(7) $(9)$ This work is licensed under a Creative Common Attribution-NonCommercial-NoDerivatives 4.0 International (CC BY-NC-ND 4.0) License. 